\title{
TARGETING NUCLEAR FACTOR KAPPA B WITH CHELATED ZINC COMPOUNDS TOWARDS ANTICANCER DRUG DESIGN
}

\section{NAGALAKSHMI K. ${ }^{1}$, SHILA S. ${ }^{1}$, INBATHAMIZH L. ${ }^{2 *}$, THENMOZHI A. ${ }^{3}$, RASAPPAN P. ${ }^{1}$, SRINIVASAN P. T. ${ }^{4}$}

${ }^{1}$ VRR Institute of Biomedical Science, Kattupakkam, Chennai 600056, India, ${ }^{2}$ Department of Biotechnology, School of Bio and Chemical Engineering, Sathyabama Institute of Science and Technology, Chennai 600119, India, ${ }^{3}$ Department of Biochemistry, SRMCollege of Arts and Science, Kattankulathur, Kanchipuram 603203, India, ${ }^{4}$ Department of Biochemistry, DG Vaishnav College, Arumbakkam, Chennai 600106, India *Email: inbathamizh.l@gmail.com

Received: 30 Mar 2021, Revised and Accepted: 07 May 2021

\section{ABSTRACT}

Objective: The objective of the study was to analyse the target-ligand interactions between nuclear factor- $\kappa \mathrm{B}(\mathrm{NF}-\kappa \mathrm{B})$ and chelated Zinc compounds and to explore the anticancer drug potential of these ligands by a bio computational approach.

Methods: Bioinformatics databases and tools were applied for the study. Three dimensional structure of the target NF- $\kappa \mathrm{B}$ was retrieved from Protein Data Bank (PDB). The optimized structures of two chelated Zinc compounds, Zinc acetate and Zinc orotate were taken for docking studies with the target using docking tool AutoDock 4.2. Drug properties of the ligands were further assessed by Molinspiration server.

Results: Docking results as predicted by AutoDock and as visualized by PyMol viewer were effective for both the ligands. Comparatively, Zinc orotate showed minimum energy and more interactions with the target. Both the ligands satisfied the Lipinski's rule of five with zero violations.

Conclusion: The findings emphasized the promising role of chelated Zinc compounds as potent drug candidates in anti-cancer drug design against NF- $\mathrm{KB}$.

Keywords: NF- $\mathrm{B}$, Chelated Zinc, Bioinformatics, Docking, Drug-design

(c) 2021 The Authors. Published by Innovare Academic Sciences Pvt Ltd. This is an open access article under the CC BY license (https://creativecommons.org/licenses/by/4.0/) DOI: https://dx.doi.org/10.22159/ijap.2021v13i4.41650. Journal homepage: https://innovareacademics.in/journals/index.php/ijap

\section{INTRODUCTION}

Nuclear factor- $\mathrm{B}(\mathrm{NF}-\kappa \mathrm{B})$ is an important protein regulating gene expressions involved in various cellular processes. It has a major role in cell proliferation, growth of tumors, metastasis, and angiogenesis contributing significantly to cancer initiation and progression [1-4]. It is a family of five transcription factors which are NF- $\kappa B 1 / p 105, N F-\kappa B 2 / p 100$, RelA/p65, RelB, and c-Rel [5]. It exists in an inactive form in the cytoplasm bound to inhibitory subunit IкB. It's active form p50/p65 can migrate to the nucleus, bind to DNA, and induce gene expressions. Interleukins (IL), inducible nitric oxide synthase (iNOS), cyclooxygenase-2 (COX-2), Tumor Necrosis Factor (TNF) and adhesion factors are some of the target genes expressed [6, 7]. Tumor regression with NF- $\kappa B$ suppression observed in earlier studies indicates the promising role of NF- $\kappa \mathrm{B}$ as a therapeutic target in anticancer studies [8-10].

Zinc is a fundamental trace mineral, essential for the proper functioning of the body through its structural, catalytic, and regulatory roles [11-13]. Its level in the body influences immune mechanisms and seems to affect reactive oxygen species (ROS) generation, granulocyte recruitment, phagocytosis, and chemotaxis $[14,15]$. It stabilizes zinc finger structures and plays a vital role in DNA replication, transcription, translation, repair mechanisms, and also in proliferation, maturation, and apoptosis of cells [16]. Cancer studies have related the disease promotion to decreased levels of Zinc [17-25]. The multiple functions performed by this element have enabled its possible role against tumor initiation and progression. But the exact mechanism behind it remains unknown [26]. The findings of earlier studies indicate the advantages of Chelated Zinc over Zinc salts in several aspects. Chelated Zinc with the metal complexed with organic ligands has more bioavailability and is easily absorbed. They also possess potential biological properties that can be applied for therapeutic purposes [27]. Zinc chelators such as TPEN (N,N,N0,N0-tetrakis-(2pyridylmethyl) ethylenediamine) have been found to prevent induction of NF-kB signaling pathway [28]. The application of chelated Zinc in inhibiting the migration of MDA-MB-231 breast cancer cells has also been identified [29].

Studies so far have indicated $N F-\kappa B$ inhibitory potential and anticancer activity of a few of the chelated Zinc compounds [28, 29].
Reports on the anticancer potential of Zinc acetate and Zinc orotate based on their interaction analysis with NF- $\mathrm{B}$ through an in silico approach are not available yet. The present study applies Bioinformatics databases and tools to reveal the significance of interactions between NF- $\kappa$ B and chelated Zinc compounds such as Zinc acetate and Zinc orotate, and the drug properties of these ligands in target-based anticancer drug design.

\section{MATERIALS AND METHODS}

\section{Target preparation}

The PDB database was used to retrieve the crystal structure of the target protein human NF- $\kappa \mathrm{B}$. Auto Dock Tool was used for optimization in adding Hydrogen atoms and assigning electronic charges to the protein atoms based on Kollman united atoms force field [30]. The PDB ID of the target protein human NF- $\kappa B$ was 1SVC.

\section{Ligand preparation}

Two chelated Zinc compounds namely Zinc acetate and Zinc orotate with the Zinc metal chelated to organic ligands were chosen as the ligands for docking with the target NF- $\mathrm{BB}$. The structures of these compounds were downloaded as SDF MOL Files from the PubChem database. The files were further converted and saved as PDB format using the Open Babel Molecular Converter program. The PubChem IDs of Zinc acetate and Zinc orotate were found to be 11192 and 108934 respectively.

\section{Molecular docking and visualization}

Docking analysis was carried out using an automated docking tool, AutoDock 4.2 to predict the binding affinity between NF- $\kappa \mathrm{B}$ and the chelated Zinc compounds [30]. Lamarckian Genetic Algorithm (LGA) was made use to study the docked conformations.

The docking suite works on the technique that performs conformation search by simulated annealing and energy evaluation by the grid-based method. The auxiliary program AutoGrid calculates grid maps for every atom type of the ligand with the grid size measuring $126 \times 126 \times 126 \AA$. The molecules of the ligand move freely within the grid box taking up six spatial degrees of freedom. A semi-empirical free energy force field evaluates initially the 
intramolecular energy in the unbound state and finally the intermolecular energy of the bound state of the ligand and the target. For each docking experiment, 10 different runs are set that stop upon reaching a maximum of 250000 energy evaluations. The results with positional root-mean-square deviation (RMSD) $>1.0 \AA$ are clustered to obtain the most favourable free energy of binding. The resulting pose is finally used for alignment with the structure of the target with the least binding energy [31].

The docked poses of the target-ligand interactions were visualized using PyMol viewer. PyMol viewer is open-source software, released under the Python License and created by DeLano. High-quality 3D images of the docked conformations can be produced by this tool [32]. Hydrogen bonding and non-bonded energies during the docking were visualized. Binding affinities, molecular dynamics, and energy simulations in docking assessments enabled the evaluation of relative stabilities.

\section{Pharmacokinetic analysis of ligands}

Certain molecular properties of compounds can be treated as their drug properties and are used to study their pharmacokinetics. These properties such as molecular weight, number of hydrogen bond donors, number of hydrogen bond acceptors, number of rotatable bonds, partition coefficient between n-octanol and water (logP), and topological polar surface area (TPSA) of the Zinc ligands were analyzed using Molinspiration server [33]. Lipinski has described these properties are essential to determine the pharmacokinetics of the drug in the body [34].

\section{RESULTS AND DISCUSSION}

\section{Structure retrieval of the target}

The crystal structure of the target protein human NF- $\kappa B$ was retrieved from PDB with ID 1SVC as shown in fig. 1. This PDB had 2.6 $\AA$ resolution, comprised major domains of the protein and had maximum coverage of the target sequence length of 365 amino acids. Hence, this PDB ID was chosen for study. The bound DNA from the structure was removed. Water molecules were also removed and Hydrogen atoms were merged with the protein successfully.

\section{Structure retrieval of the ligands}

The compatible format of the ligands Zinc acetate and Zinc orotate was obtained and the retrieved structures of the ligands were as represented in fig. 2 and fig. 3.

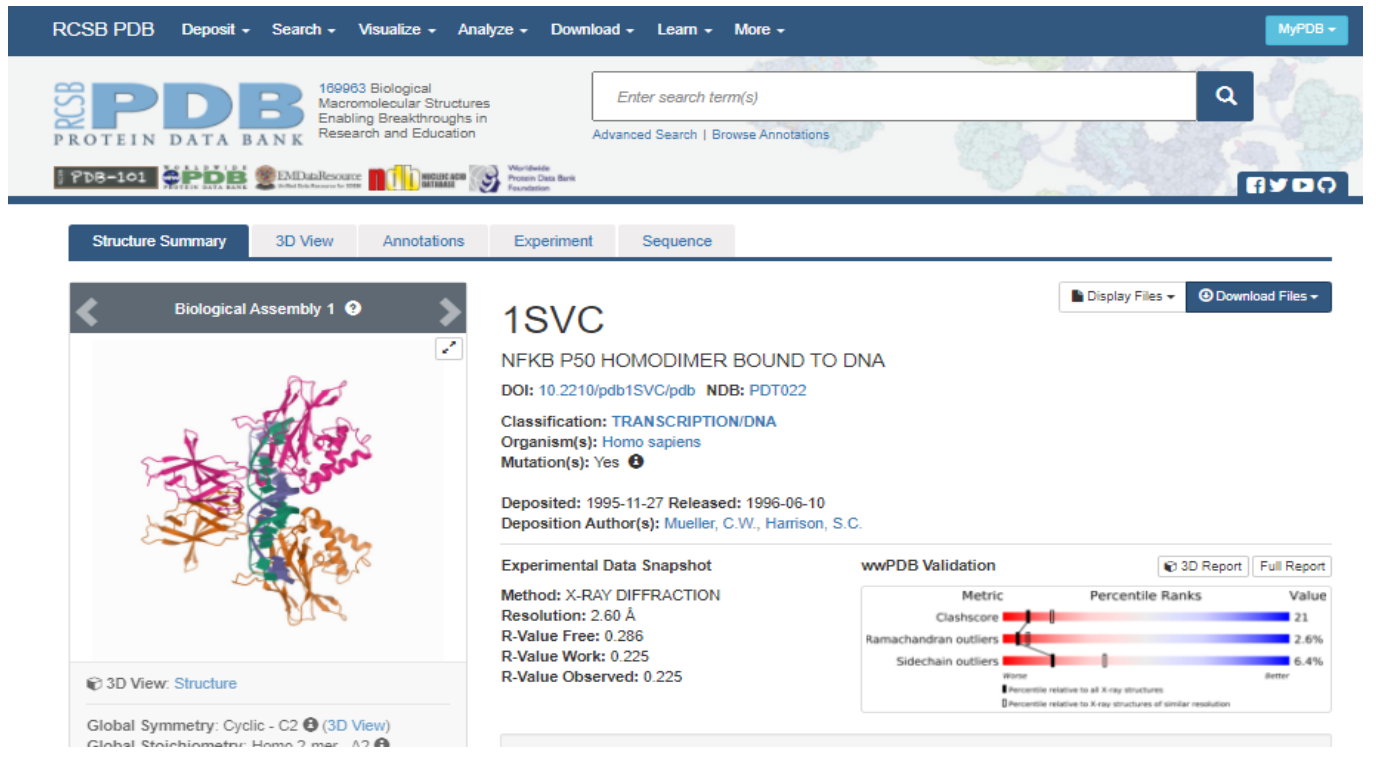

Fig. 1: PDB Structure of NF-kB<smiles>CC(=O)O[18O]C(C)=O</smiles>

Fig. 2: Zinc acetate structure<smiles>O=C(O[18O]C(=O)c1cc(=O)[nH]c(=O)[nH]1)c1cc(=O)[nH]c(=O)[nH]1</smiles>

Fig. 3: Zinc orotate structure

\section{Docking results}

LGA determined the interactions between NF- $\mathrm{KB}$ and the chelated Zinc compounds as 10 conformers. Based on the minimal solvent accessibility and lowest energy, the best-docked conformer was selected. Two major steps were involved in the docking analysis. In the first step, the exact orientation of the conformers in the best active site was predicted. The second step determined the strength of the target-ligand interactions by scoring [35]. The conformations of the docked poses were obtained by AutoDock with Target-Ligand interactions as in fig.4 (A) and (B). The energy and Hydrogen bond details of Zinc acetate and Zinc orotate docked individually to NF- $\kappa B$ in the final conformations were presented in table 1 . The PyMol viewer visualization images of the interactions were illustrated in fig. 5 (A) and (B). The atoms involved in the interactions of the ligands with the target along with their bond length as visualized by the PyMol viewer were tabulated in table 2 and table 3. The results indicated that Zinc orotate showed more interactions than Zinc acetate with the target. 9 Zinc orotate-target interactions and 4 Zinc acetate-target interactions were observed by PyMol viewer. AutoDock predicted $4 \mathrm{H}$-bonds between Zinc orotate-target and $3 \mathrm{H}$ bonds between Zinc acetate-target. The docking score was expressed in terms of binding energy. The binding energy of the Zinc orotate-target complex $\left(-8.77 \mathrm{kcal} \mathrm{mol}^{-1}\right)$ seemed to be lesser than that of the Zinc acetate-target complex $\left(-5.54 \mathrm{kcal} \mathrm{mol}^{-1}\right)$ indicating greater stability of the former than the latter. The stability of the confirmation was based on the minimum docking value and the maximum number of interactions and it seemed to be more for Zinc orotate [36]. This specified that Zinc orotate was a more potent inhibitor of NF-KB. On the whole, both the chelated Zinc compounds 
showed significant docking results with less binding energies and more number of H-bond interactions. PyMol viewer indicated that Zinc in both the ligands interacted with the Arginine57 residue of the target. This highlighted the significance of Zinc in contributing towards the drug properties of these compounds as effective inhibitors of NF- $\mathrm{\kappa B}$.

\section{Drug properties and pharmacokinetics of ligands}

It is essential to study the physicochemical and pharmacokinetic properties of drug compounds to avoid their adverse reactions [37]. In the present study, the results of Molinspiration evaluated the drug likeliness of the selected Zinc chelate compounds as presented in table 4. The results seemed to be very promising for both the compounds, satisfying Lipinski's rule of five with zero violations. These molecular descriptors were found to be widely accepted as the major attributing factors of drug likeliness in drug discovery and development [38]. Zinc orotate possessed a greater number of H-bond donors and acceptors compared to Zinc acetate. This might have accounted for the greater number of $\mathrm{H}$-bond interactions of Zinc orotate with the target. TPSA of both the compounds was found to be less than $140 \AA^{2}$.

Their rotatable bonds were also less than 10. Compounds following these criteria were proven to be associated with good absorption and bioavailability [39]. LogP values of these compounds less than 5 obeying Lipinski's rule indicated that these compounds had good aqueous solubility and less risk of plasma protein binding and tissue accumulation.

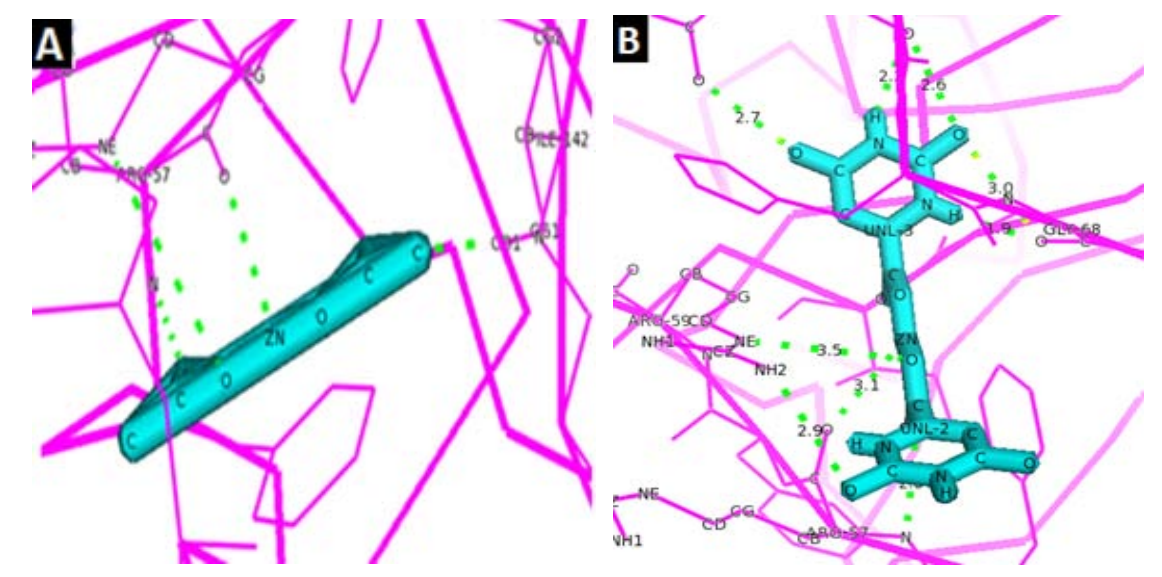

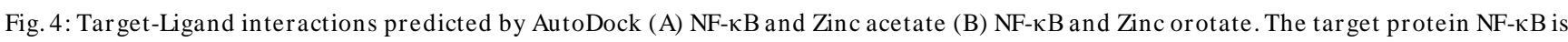
represented as lines. The interacting Zinc compound is in stick model. Interacting atoms are highlighted. Interactions are denoted by green dotted lines

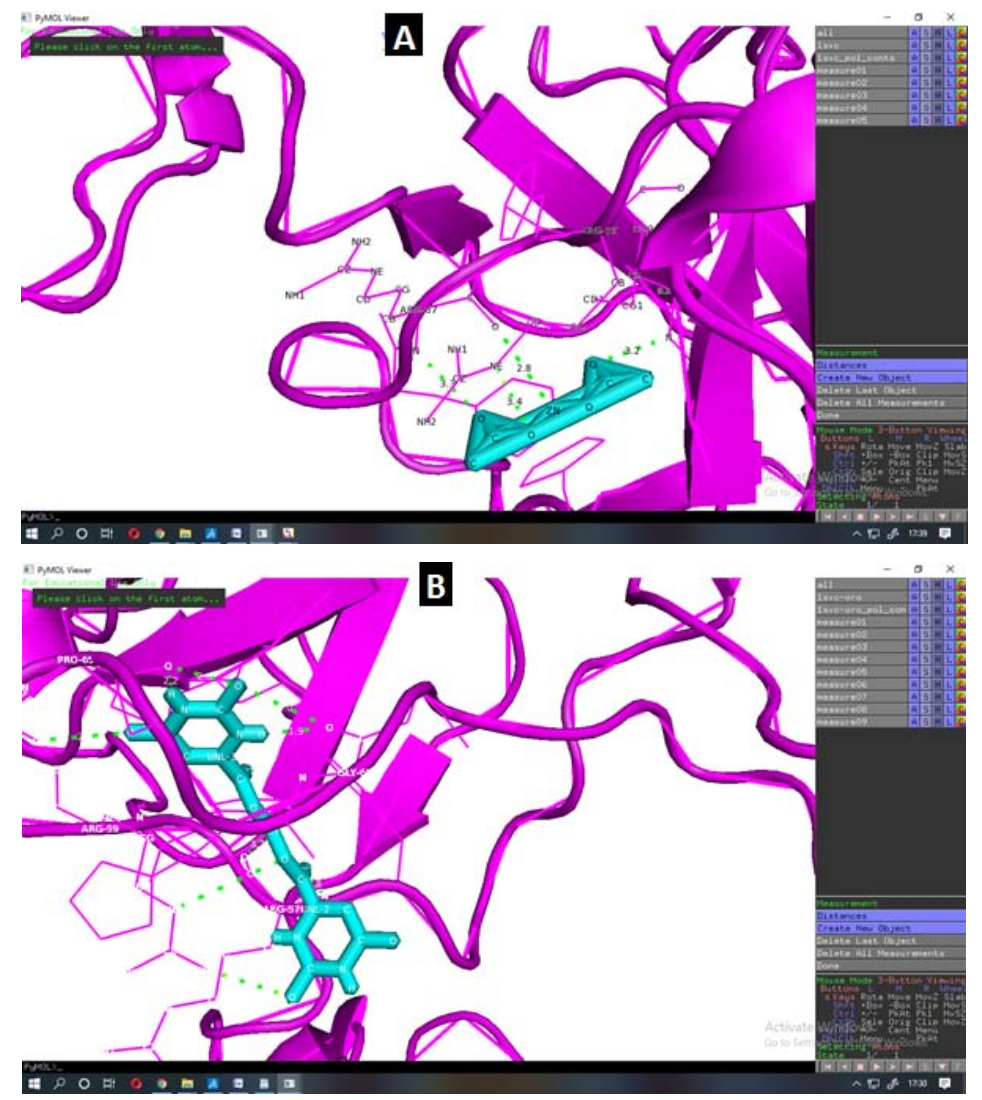

Fig. 5: Docked poses by PyMol viewer. (A) Interactions between NF- $\mathrm{B}$ and Zinc acetate (B) Interactions between NF- $\mathrm{B}$ and Zinc orotate. The target protein NF-KB is represented as ribbon model in pink. The interacting Zinc compound is in blue as a stick model. The interactions are in dotted green lines 
Table 1: Docking details as predicted by AutoDock (A) Interactions between NF- $\kappa B$ and Zinc acetate (B) Interactions between NF- $\kappa B$ and Zinc orotate

\begin{tabular}{lll}
\hline Docking results & Zinc acetate & Zinc orotate \\
\hline Binding Energy & -5.54 & -8.77 \\
Ligand efficiency & -0.62 & -0.38 \\
Inhibition constant & 87.64 & 370.91 \\
Hydrogen bonds & 3 & 4 \\
\hline
\end{tabular}

Table 2: Docking details of zinc acetate by PyMol viewer

\begin{tabular}{|c|c|c|c|}
\hline \multicolumn{2}{|l|}{ NF-кB } & \multirow{2}{*}{ Zinc acetate } & \multirow[t]{2}{*}{ Distance (Angstrom unit) } \\
\hline Residue & Atom & & \\
\hline ILE142 & $\mathrm{N}$ & 0 & 3.2 \\
\hline ARG57 & 0 & $\mathrm{Zn}$ & 2.8 \\
\hline ARG57 & $\mathrm{N}$ & 0 & 3.3 \\
\hline ARG59 & $\mathrm{NE}$ & 0 & 3.4 \\
\hline
\end{tabular}

Table 3: Docking details of zinc orotate by PyMol viewer

\begin{tabular}{|c|c|c|c|}
\hline \multicolumn{2}{|l|}{ NF-кB } & \multirow[t]{2}{*}{ Zinc orotate } & \multirow[t]{2}{*}{ Distance (Angstrom unit) } \\
\hline Residue & Atom & & \\
\hline ARG59 & $\mathrm{NE}$ & 0 & 3.5 \\
\hline ARG59 & $\mathrm{NH}_{2}$ & 0 & 2.9 \\
\hline ARG57 & $\mathrm{N}$ & OXT & 2.8 \\
\hline ARG57 & 0 & $\mathrm{Zn}$ & 3.1 \\
\hline GLY68 & 0 & $\mathrm{H}$ & 1.9 \\
\hline GLY68 & 0 & 0 & 3.0 \\
\hline PR065 & 0 & 0 & 2.6 \\
\hline PR065 & 0 & $\mathrm{H}$ & 2.2 \\
\hline GLY64 & 0 & 0 & 2.7 \\
\hline
\end{tabular}

Table 4: Drug-likeliness of zinc acetate and zinc orotate

\begin{tabular}{lll}
\hline Property name & Zinc acetate & Zinc orotate \\
\hline Molecular Weight $\left(\mathrm{g} \mathrm{mol}^{-1}\right)$ & 183.5 & 155.09 \\
Hydrogen Bond Donor Count & 0 & 2 \\
Hydrogen Bond Acceptor Count & 4 & 6 \\
Rotatable Bond Count & 0 & 1 \\
miLogP & -2.78 & -3.94 \\
TPSA & 40.13 & 105.85 \\
n-violations & 0 & 0 \\
\hline
\end{tabular}

Scientific evidence further substantiated the anticancer role of the zinc compounds targeting NF- $\kappa$ B. Earlier studies have related zinc finger-containing proteins to inhibition of NF- $\kappa B$ activation [7]. Zinc could modulate the activity of NF- $\mathrm{kB}$ through reversible inhibition of cyclic nucleotide phosphodiesterase (PDE) [40]. An increase in the expression of peroxisome proliferator-activated receptor (PPAR) by Zinc also accounted for the inhibition of NF- $\mathrm{KB}$ activation. The increased PPAR further down-regulated inflammatory reactions and molecules involved [41]. Zinc possessed significant antioxidant potential and prevented the generation of toxic free radicals $[42,43]$. It also seemed to be capable of eliminating cancer-causing mutant forms which ensured its anticancer potential [44]. Chelated Zinc compounds were found to inhibit the migration of cancer cells which was absent in the case of chelated copper and iron [29].

\section{CONCLUSION}

This study reveals the interactions of chelated Zinc compounds such as Zinc acetate and Zinc orotate with NF-kB, a potent cancer target. Computational assessments employed, present a potential platform for the novel selection of effective ligands that may find application in chemotherapy. The significant interactions of chelated Zinc compounds with NF-KB and their favourable drug properties may emphasize the promising therapeutic value of these compounds to combat cancer.

\section{FUNDING}

\section{AUTHORS CONTRIBUTIONS}

All the authors have contributed equally.

\section{CONFLICT OF INTERESTS}

The authors declare no conflict of interest.

\section{REFERENCES}

1. Gammoh NZ, Rink L. Zinc in infection and inflammation. Nutrients 2017;9:624.

2. Kumar A, Takada Y, Boriek AM, Aggarwal BB. Nuclear factor$\kappa B$ : Its role in health and disease. J Mol Med 2004;82:434-48.

3. Tergaonkar V. NF- $\mathrm{kB}$ pathway: a good signaling paradigm and therapeutic target. Int J Biochem Cell Biol 2006;38:1647-53.

4. Zingarelli B. Nuclear factor-B. Crit Care Med 2005;33:S414S416.

5. Xia Y, Shen S, Verma IM. NF- $\kappa B$, an active player in human cancers. Cancer Immunol Res 2014;2:823-30.

6. Ghosh S, Karin M. Missing pieces in the NF-кB puzzle. Cell 2002;109:S81-S96.

7. Jarosz M, Olbert M, Wyszogrodzka G, Mlyniec K, Librowski T. Antioxidant and anti-inflammatory effects of zinc. Zinc-dependent NF- $\mathrm{BB}$ signaling. In flammopharmacology 2017;25:1124.

8. Meylan E, Dooley AL, Feldser DM, Shen L, Turk E, Ouyang C, et al. Requirement for NF-kappaB signalling in a mouse model of lung adenocarcinoma. Nature 2009;462:104-7. 
9. Xia Y, Yeddula N, Leblanc M, Ke E, Zhang Y, Oldfield E, et al. Reduced cell proliferation by IKK2 depletion in a mouse lung cancer model. Nat Cell Biol 2012;14:257-65.

10. Basseres DS, Ebbs A, Levantini E, Baldwin AS. Requirement of the NF-kappaB subunit p65/RelA for K-Ras-induced lung tumorigenesis. Cancer Res 2010;70:3537-346.

11. Faa G, Nurchi VM, Ravarino A, Fanni D, Nemolato S, Gerosa C, et al. Zinc in gastrointestinal and liver disease. Coord Chem Rev 2008;252:1257-69.

12. Fukada T. Zinc biology and zinc signaling. Biomed Res Trace Elem 2015;26:1-6.

13. Zastrow ML, Pecoraro VL. Designing hydrolytic zinc metalloenzymes. Biochemistry 2014;53:957-78.

14. Hasan R, Rink L, Haase H. Chelation of free Zn2+Impairs chemotaxis, phagocytosis, oxidative burst, degranulation, and cytokine production by neutrophil granulocytes. Biol Trace Elem Res 2016;171:79-88.

15. Oteiza PI. Zinc and the modulation of redox homeostasis. Free Radical Biol Med 2012;53:1748-59.

16. Krishna SS, Majumdar I, Grishin NV. Structural classi fication of zinc fingers: Survey and summary. Nucleic Acids Res 2003;31:532-50.

17. Stepien M, Hughes DJ, Hybsier S, Bamia C, Tjønneland A, Overvad K, et al. Circulating copper and zinc levels and risk of hepatobiliary cancers in Europeans. Br J Cancer 2017;116:688-96.

18. Kumar R, Razab S, Prabhu K, Ray S, Prakash B. Serum butyrylcholinesterase and zinc in breast cancer. J Cancer Res Ther 2017;13:367-70.

19. Khoshdel Z, Naghibalhossaini F, Abdollahi K, Shojaei S, Moradi MS, Malekzadeh M. Serum copper and zinc levels among iranian colorectal cancer patients. Biol Trace Elem Res 2015;170:294-9.

20. Okunade KS, Dawodu OO, Salako O, Osanyin GE, Okunowo AA, Anorlu RI. Comparative analysis of serum trace element levels in women with invasive cervical cancer in lagos, Nigeria. Pan Afr Med J 2018;31:194.

21. Zablocka Slowinska K, Placzkowska S, Prescha A, Pawelczyk K, Porebska I, Kosacka M, et al. Serum and whole blood Zn, Cu and Mn profiles and their relation to redox status in lung cancer patients. J Trace Elem Med Biol 2018;45:78-84.

22. Wang Y, Sun Z, Li A, Zhang Y. Association between serum zinc levels and lung cancer: a meta-analysis of observational studies. World J Surg Oncol 2019;17:1-8.

23. Emami A, Nazem MR, Shekarriz R, Hedayati M. Micronutrient status (calcium, zinc, vitamins D and E) in patients with medullary thyroid carcinoma: a cross-sectional study. Nutrition 2017;41:86-9.

24. Lu H, Cai L, Mu LN, Lu QY, Zhao J, Cui Y, et al. Dietary mineral and trace element intake and squamous cell carcinoma of the esophagus in a Chinese population. Nutr Cancer 2006;55:63-70.

25. Bidoli E, Bosetti C, La Vecchia C, Levi F, Parpinel M, Talamini R, et al. Micronutrients and laryngeal cancer risk in Italy and switzerland: a case-control study. Cancer Causes Control 2003;14:477-84.

26. Dhawan DK, Chadha VD. Zinc: a promising agent in dietary chemoprevention of cancer. Indian J Med Res 2010;132:676-82.
27. Lin S, Lin X, Yang Y, Li F, Luo L. Comparison of chelated zinc and zinc sulfate as zinc sources for growth and immune response of shrimp (Litopenaeus vannamei). Aquaculture 2013;406:79-84.

28. Sandstead HH, Prasad AS, Penland JG, Beck FWJ, Kaplan J, Egger $\mathrm{NG}$, et al. Zinc deiciency in Mexican American childre n: Influence of zinc and other micronutrients on T cells, cytokines, and antiiflammatory plasma proteins. Am J Clin Nutr 2008;88:1067-73.

29. Kagara N, Tanaka N, Noguchi S, Hirano T. Zinc and its transporter ZIP10 are involved in the invasive behavior of breast cancer cells. Cancer Sci 2007;98:692-7.

30. Morris GM, Goodsell DS, Halliday RS. Automated docking using a lamarckian genetic algorithm and an empirical binding free energy function. J Comput Chem 1998;19:1639-62.

31. Blum C, Roli A, Sampels M. Hybrid metaheuristics: an emerging approach to optimization. Springer; 2008.

32. DeLano WL. The PyMOL molecular graphics system. San Carlos: DeLano Scientific; 2002.

33. Jarrahpour A, Fathi J, Mimouni M, Ben Hadda T, Sheikh J, Chohan Z, et al. Petra, osiris and molinspiration (POM) together as successful support in drug design: antibacterial activity and biopharmaceutical characterization of some azo Schiff bases. Med Chem Res 2012;21:1984-90.

34. Lipinski CA. Lead-and drug-like compounds: the rule-of-five revolution. Drug Discovery Today Technol 2004;1:337-41.

35. Wang R, Lu Y, Wang S. Comparative evaluation of 11 scoring functions for molecular docking. J Med Chem 2003;46:2287-303.

36. Inbathamizh L, Shyamala Devi K, Sri Vaishnavi Taarikaa S, Mithula P, Vennela KN. Targeting cytochrome P450 1A1 enzyme with crucifer photo components: an in silico approach for chemopreventive drug design against lung cancer. Asian J Pharm 2020;14:51-7.

37. Inbathamizh L, Padmini E. Quinic acid as a potent drug candidate for prostate cancer. Asian J Pharm Clin Res 2013;6:106-12.

38. Leeson PD, Springthorpe B. The influence of drug-like concepts on decision-making in medicinal chemistry. Nat Rev Drug Discovery 2007;6:881-90.

39. Veber DF, Johnson SR, Cheng HY, Smith BR, Ward KW, Kopple KD. Molecular properties that influence the oral bioavailability of drug candidates. J Med Chem 2002;45:2615-23.

40. Ke H. Implications of PDE4 structure on inhibitor selectivity across PDE families. Int J Impot Res 2004;16:S24-S27.

41. Lemberger T, Desvergne B, Wahli W. Peroxisome proliferatoractivated receptors: a nuclear receptor signaling pathway in lipid physiology. Annu Rev Cell Dev Biol 1996;12:335-63.

42. Strange RW, Antonyuk S, Hough MA, Doucette PA, Rodriguez JA, Hart PJ, et al. The structure of holo and metal-deficient wild-type human $\mathrm{Cu}, \mathrm{Zn}$ superoxide dismutase and its relevance to familial amyotrophic lateral sclerosis. J Mol Biol 2003;328:877-91.

43. Zelko IN, Mariani TJ, Folz RJ. Superoxide dismutase multigene family: a comparison of the CuZn-SOD (SOD1), Mn-SOD (SOD2), and EC-SOD (SOD3) gene structures, evolution, and expression. Free Radical Biol Med 2002;33:337-49.

44. John E, Laskow TC, Buchser WJ, Pitt BR, Basse PH, Buttefield $\mathrm{LH}$, et al. Zinc in innate and adaptive tumor immunity. J Transl Med 2010;8:118. 